\title{
0 financiamento da educação infantil: em foco o FUNDEB e os desdobramentos com o fim da vigência da lei
}

\author{
Andressa Braga Busmeyer Fernandes ${ }^{1}$ \\ https://orcid.org/0000-0003-3280-9552 \\ Camila Maria Bortot ${ }^{2}$ \\ https://orcid.org/0000-0002-9355-8876 \\ Maria Nilvane Fernandes ${ }^{3}$ \\ https://orcid.org/0000-0002-3420-2714
}

\begin{abstract}
Resumo
O presente artigo localiza-se dentre as pesquisas de políticas educacionais, nas questões relativas ao financiamento da educação infantil. Como objeto de estudo foi selecionado o Fundo de Manutenção e Desenvolvimento da Educação Básica e de Valorização dos Profissionais da Educação (Fundeb) e suas relações com a educação infantil. Objetivou-se apreender a importância do financiamento na manutenção e na qualidade da educação infantil, bem como as consequências relacionadas ao fim de sua vigência. Conclui-se que discutir sua revisão é debater a implantação do Custo-Aluno-Qualidade Inicial e o CustoAluno-Qualidade. Além disso, lançar o olhar para o fato de que há mais avanços do que retrocessos sobre as políticas de fundos redistributivos como maneira de equalização da educação básica, sobretudo, na educação infantil e, que sem isso, a precarização se acirra e a qualidade não é alcançada.
\end{abstract}

Palavras-chave: Política Educacional. Financiamento. Fundeb. Educação Infantil.

\begin{abstract}
This article is located among the researches of educational policies, in which the financing of / in early childhood education was delimited by theme. As an object we selected FUNDEB and its relations with Early Childhood Education, analyzing its impacts with the end of its term in 2020. The objective was to understand the impact of funding on the maintenance and quality of early childhood education, in particular FUNDEB and consequences about the end of the fund's life. It concludes that discussing its revision is to debate the implementation of CAQi and CAQ, besides launching the view that there are more advances than limits on redistributive funds policies as a way of equalizing basic education, especially in early childhood education, and without it, precariousness intensifies and quality is not achieved.
\end{abstract}

Keywords: Educational Policy. Financing. Fundeb. Childhood education.

\footnotetext{
${ }^{1}$ Especialista em políticas educacionais pela Universidade Federal do Paraná. Pedagoga pela Universidade Federal do Paraná. Filósofa pela Fą culdade Padre João Bagozzi. E-mail: andressabragabusmeyer@hotmail.com

${ }^{2}$ Doutoranda pela Universidade Federal do Paraná, na linha de políticas educacionais. Mestra em educação pela Universidade Estadual de Maringá (UEM), na linha de políticas e gestão da educação. Pedagoga pela UEM. Bolsista pela Coordenação de Aperfeiçoamento de Pessoal de Nível Superior (CAPES). E-mail: camilabortot@hotmail.com

3 Graduada em pedagogia com habilitação em orientação educacional e supervisão escolar. Doutoramento sanduíche no Instituto de Lisboa - fomento programa de doutorado sanduíche no exterior PDSE - CAPES. Mestre e Doutora em Educação na linha de Políticas educacionais (UEM), docente do departamento de teoria e fundamento (DFT) da faculdade de educação (FACED) e do programa de pós-graduação em educação PPGE da Universidade Federal do Amazonas (UFAM). E-mail: nilvane@gmail.com
} 


\section{Introdução}

O tema presente circunscreve a área das relações entre política educacional e financiamento. Por ser um tema amplo e fundamental para o debate, delimitou-se por objeto de pesquisa o financiamento da educação infantil e os limites, os avanços e os desafios do Fundo de Manutenção e Desenvolvimento da Educação Básica e de Valorização dos Profissionais da Educação (Fundeb) que encerrará sua vigência em 2020. Para tanto, por meio de pesquisa bibliográfica e documental, com abordagem qualitativa, utilizou-se como fontes os seguintes documentos como principais: a Constituição da República Federativa do Brasil de 1988, doravante CF/88, a Lei de Diretrizes e Bases (LDB), o Estatuto da Criança e do Adolescente (ECA) e o Plano Nacional de Educação (PNE). Além desses documentos normativos, outros de caráter orientador deram aportes para analisar elementos sobre financiamento, educação infantil, direito à educação, qualidade da educação.

A começar pela Carta Magna, destaca-se o Brasil como um dos poucos países do mundo a designar, constitucionalmente, orçamento à educação (TOMASEVSKI, 2006). O artigo 212 da CF/88 (BRASIL, 1988) prevê que a União não poderá aplicar menos de 18\%, e os Estados, o Distrito Federal - doravante DF - e os Municípios, menos de $25 \%$ das receitas resultantes de impostos para a educação, especificamente com despesas de Manutenção e Desenvolvimento do Ensino (MDE). Nessa perspectiva, a alocação obrigatória de recursos é parte fundamental, pois assegura o direito à educação (TOMASEVSKI, 2006).

Entretanto, os atuais fundamentos para financiamento da educação infantil, bem como de toda a educação básica pública brasileira, estabelecidos na $\mathrm{CF} / 88$, sofreram modificações importantes por meio das Emendas Constitucionais (EC) $\mathrm{n}^{\mathrm{o}}$ 14, de setembro de 1996 (BRASIL, 1996a), e $\mathrm{n}^{\circ}$ 53, de dezembro de 2006 (BRASIL, 2006). Essas ECs redefiniram as responsabilidades de Estados e Municípios, bem como a trajetória dos recursos financeiros.

A partir da EC n 14 de 1996, é sancionado, no parágrafo $2^{\circ}$ do artigo 211 da CF/88, que os Municípios atuarão prioritariamente no ensino fundamental e na educação infantil. Enquanto, no parágrafo $3^{\circ}$, delimita-se aos Estados e ao DF a atuação, prioritariamente, no ensino fundamental e médio. Há ainda uma ressalva, a partir da EC n ${ }^{\circ} 53$ de 2006, para que Estados e DF ajudem a manter, por meio de cooperação técnica e financeira da União e do Estado, programas de educação infantil e de ensino fundamental.

Ainda, de acordo com a EC nº 14 de 1996, cabe à União financiar as instituições de ensino públicas federais e exercer função redistributiva e supletiva. $\mathrm{O}$ objetivo é garantir a equalização de oportunidades educacionais e o padrão mínimo de qualidade do ensino por meio de assistência técnica e financeira aos Estados, ao DF e aos Municípios (BRASIL, 1996).

Representando uma forte intervenção nas relações entre os entes federados, no que diz respeito a responsabilidades educacionais, especialmente entre os Estados e entre os Municípios de uma mesma unidade federada, foi criado o Fundo de Manutenção e Desenvolvimento do Ensino Fundamental e de Valorização do Magistério (Fundef), por intermédio da EC nº 14 de 1996, a qual vigorou de 1998 a 2006 (PINTO, 2015; ARAÚJO, 2019). Apesar desse Fundo abranger apenas o ensino fundamental e a valorização de professores, destacamos os principais impactos.

O primeiro deles foi uma mudança radical na distribuição da oferta do ensino fundamental no interior dos entes federados. Com a aprovação do Fundef, a participação foi progressivamente crescendo, atingindo $64 \%$ em 
2012 (PINTO, 2015; 2018). Outra característica é que o processo foi mais acentuado nas regiões mais pobres do país, as quais já eram as mais municipalizadas (PINTO, 1989), e mesmo nas mais ricas, como São Paulo, a transferência de matrículas foi expressiva, saltando de 10\% do total público na década de 1990 para quase 50\% em 2012, quintuplicando a responsabilidade municipal (PINTO, 2015; 2018).

Com o fim da vigência do Fundef, o Fundeb foi implementado abrangendo toda a educação básica, incluindo, portanto, a educação infantil, tendo em vista seu reconhecimento a partir da LDB n ${ }^{\circ}$ 9.394/96 (BRASIL, 1996), como a primeira etapa da educação básica. Instituído em cada uma das unidades da Federação, como um fundo de natureza contábil, o Fundeb passou a reter um volume substancial da receita gerada pela vinculação de recursos municipais e estaduais (BASSI, 2011) redistribuindo-a de forma equitativa e proporcional ao número de matrículas na educação básica, mantidos por essas esferas de governo, de acordo com suas responsabilidades educacionais (BRASIL, 2006a; 2006; 2007b).

Nesse sentido, para analisar os desdobramentos do fim da vigência do Fundeb para a educação infantil, fazse necessário debruçar-se sobre o percurso histórico da política de financiamento como fundamento da promoção da qualidade e da equalização. Esses, mais recentemente, vêm constituindo esforços para buscar ferramentas para promover a qualidade da educação por meio do Custo-Aluno-Qualidade (CAQ) e o Custo-Aluno-Qualidade Inicial (CAQi) a fim de equalizar custos, previsto em Lei, para o Fundeb.

Tendo em vista as mudanças na CF/88, que tonaram obrigatória a educação de crianças de 4 e 5 anos, bem como as metas da ampliação do atendimento à primeira infância previsto no PNE (Lei no 13.005 de 2014), além do processo de municipalização e responsabilização dos Municípios sobre os custos do ensino fundamental e da educação infantil, somados à progressão da organização do CAQ e CAQi em busca do custo de uma educação de qualidade (PINTO, 2015) chegou-se à seguinte questão-problema: qual a influência do financiamento na manutenção e qualidade da educação básica, e nela a educação infantil, com possibilidade do fim da vigência do Fundeb?

Para responder à pergunta de pesquisa, traçou-se como objetivo geral apreender a importância do financiamento para a qualidade da educação infantil, bem como as implicações com o fim de sua vigência em 2020. Alinhado a isso, delimitou-se três objetivos específicos quanto à educação infantil: esquematizar o histórico da origem do financiamento; analisar o financiamento com base na qualidade, a partir da perspectiva do gastoaluno e do CAQ e, por fim, identificar os avanços e os limites do Fundeb para a qualidade, além dos novos desafios com o vencimento do fundo chegando próximo.

\section{Educação infantil e seus marcos legais (1988-2014)}

O reconhecimento da educação infantil como parte da educação básica é recente no Brasil, sendo assim, os documentos mandatórios (publicados entre 1988 e 2014), com peso de Lei, são utilizados para traçar o histórico da primeira infância e do financiamento da educação. Nesse sentido, a CF/88 representa o marco do reconhecimento da educação infantil como primeira etapa da educação básica. Por sua vez, o ECA reconhece a criança como sujeito de direito, enquanto a LDB assegura a educação gratuita a essa faixa etária, até então pouco reconhecida. Em 2014, com o PNE definem-se as metas para educação infantil. 
Diante disso, a CF/88, ao garantir à educação um destaque enquanto direito do ser, despertou os olhares para a primeira infância e para a criança enquanto sujeito de direito. "Verifica-se, portanto, que a 'Constituição Cidadã', foi mais ousada que as suas antecessoras ao elevar a educação ao patamar de direito fundamental, objetivo fundamental e direito social da República Federativa do Brasil [...]” (BARROS, 2008, p. 3).

$O$ artigo $6^{\circ}$ da $\mathrm{CF} / 88$ enfatiza a defesa da criança e da educação, tendo sido modificada pela $E C \mathrm{n}^{\circ} 60$, de 15 de setembro de 2015. Essa EC complementa alguns direitos fundamentais, garantindo direito também à saúde, à segurança, à moradia, à alimentação, ao trabalho e à proteção da maternidade. Por sua vez, o artigo 227 quebra paradigmas a respeito da criança enquanto receptor das vontades externas, desse modo reconhecendo na criança o sujeito de direito, mas que ainda precisa ser cuidado; sendo assim, define também seus responsáveis.

Tais artigos garantem, grosso modo, o direito da criança sem grandes delimitações, mas é no artigo 208 que vemos a expressão educação infantil enquanto direito, bem como a garantia a seu acesso como dever do Estado. Nesse viés, cabe ressaltar a modificação dessa lei a partir da EC n ${ }^{0} 53$ de 2006, a qual reduz a idade para atendimento das crianças nas creches, para 0 a 3 anos, e na pré-escola, para 4 e 5 anos. Ademais, a EC no 59 de 11 de novembro de 2009 determina o atendimento a toda criança de 4 anos como obrigatório.

Assim a EC no 53 reduziu a idade para ingresso na educação infantil de 6 para 5 anos. Outra modificação foi a criação do Fundeb como substituto do Fundef, mudança importante descrita por Oliveira (2009, p. 50):

Verificou-se que as emendas n. ${ }^{0}$ 14/1996 e n. ${ }^{\circ}$ 53/2006 formalizam importante veio das reformas educacionais implementadas na educação básica pelos governos Fernando Henrique Cardoso e Luís Inácio Lula da Silva, instituindo a política de fundos não só como recurso de distribuição e controle dos gastos educacionais, mas como recurso de regulação da ação federativa dos entes subnacionais em relação às políticas educacionais.

É importante ressaltar que a CF/88 define o Estado como responsável pela educação da criança pequena, contudo, assegurar a oferta e o dever do Estado em relação à educação não garante as condições nas quais essa ocorrerá. Sendo assim, o artigo 206 destaca a informação de garantia de acesso e permanência para uma educação de qualidade.

Quanto ao inciso VII, entende-se que garantir padrão de qualidade é condição que jamais se pode perder de vista, visto que na história da Educação Infantil brasileira a marca de sua origem e de sua expansão sempre foi a precariedade. Quantidade e ampliação precisam combinar-se com qualidade na oferta e acesso a todos que o queiram (MOREIRA; LARA, 2012, p. 127).

A partir dos princípios da CF/88, a LDB (BRASIL, 1996) regulamenta a educação brasileira. Para a educação infantil, a promulgação da LDB demonstra o reconhecimento dessa etapa como parte da educação. Sobre isso, Barros (2008) explica que um dos avanços do reconhecimento da educação infantil como primeira etapa da educação básica é mais do que determinar à qual área a educação infantil fará parte; é integrá-la ao sistema de ensino a fim de acatar as diretrizes e normas do Conselho Nacional de Educação (CNE).

No que diz respeito ao provimento da educação infantil, a LDB, segundo Barros (2008), em seu artigo $4^{\circ}$, destaca a inserção da palavra gratuidade, que até então não estava garantida a essa modalidade de ensino pela $\mathrm{CF} / 88$, obrigando, assim, os entes federados a se responsabilizarem pela promoção dessa etapa de ensino. Ao garantir legalmente a gratuidade do ensino, permite-se a cobrança judicial da administração pública quanto a ofertar o ensino; sendo facultativo ao cidadão usufruir. 
Por fim, o PNE, Lei $n^{\circ} 10.172 / 2001$, foi criado para cumprir com o estipulado tanto pela CF/88 quanto pela LDB, quando se definiu, no artigo $9^{\circ}$, o papel da União em colaboração com Estados e Municípios para criação de um plano nacional com vigência decenal, com avaliações bienais, a fim de se tornar uma política pública de estado - com ação de continuidade, independente do governo que assume, deve ser realizada por ser amparada pela legislação - e não uma política de governo - descontinuada, com menor durabilidade e que muda a cada governo. $\mathrm{Na} \mathrm{CF} / 88$ tal garantia se encontra no art. 214, o qual descreve os objetivos a serem alcançados pelas metas do PNE, baseadas na erradicação do analfabetismo; na universalização do atendimento escolar; na melhoria da qualidade de ensino; na formação para o trabalho; e, por fim, na promoção humanística, científica e tecnológica. De acordo com a página oficial do PNE, seu objetivo é determinar diretrizes, metas e estratégias para as políticas educacionais.

O primeiro PNE teve vigência entre 2001 a 2010, no governo de Fernando Henrique Cardoso (1995-2003), sua elaboração estava pautada mais nas questões políticas e econômicas do que realmente educacionais. "Ao apresentar o processo de elaboração do PNE e constatar as influências neoliberais, os interesses econômicos nele contidos e o descaso do Estado em relação a ser esse plano discutido e elaborado no âmbito educacional [...]" (MOREIRA; LARA, 2012, p. 141).

Segundo Moreira e Lara (2012), o PNE (2001-2010) determinou metas quanto à ampliação de vagas, ao padrão de qualidade, à infraestrutura, à autorização de funcionamento, à formação de professores, à garantia de alimentação em estabelecimentos públicos e conveniados, ao acesso a materiais adequados à faixa etária, bem como a padrões de supervisão, controle e avaliação. Ressalta-se que essas metas exigem financiamento para sua efetivação.

Referente à educação infantil, Moreira e Lara (2012) destacaram as metas 20, 21, 23 e 25 do PNE. A primeira visa debates com a sociedade civil sobre o direito de trabalhadores ao acesso gratuito dos seus filhos às creches. A segunda busca assegurar 10\% do MDE, não vinculados ao Fundef, aplicados na educação infantil. A terceira deve realizar estudos sobre os custos da educação infantil. E, por fim, a última objetiva uma ação supletiva da União e dos Estados juntos aos Municípios.

Atualmente, está em vigor o PNE 2014-2024, o qual foi formulado com 20 metas e 254 estratégias. Segundo Ximenes e Grinkraut (2014, p. 79):

O PNE, longe de significar o esgotamento de um ciclo de regulamentação do direito à educação, abre uma nova etapa de proteção jurídica e de planejamento público para sua efetivação, na qual está prevista a edição de novas normas, além da revisão e adequação de políticas em curso, tendo como instrumento principal, no âmbito local, os planos de educação dos municípios e estados.

Martins (2015) destaca que, diferente do PNE 2001-2010, no qual grande parte das metas voltadas ao financiamento foram vetadas, o segundo PNE foi elaborado reconhecendo de antemão a necessidade de destinar verba suficiente para uma educação de qualidade. Nesse sentido,

[...] ao PNE foi atribuída uma função específica em relação ao financiamento da educação: definir os termos da distribuição de recursos para o ensino obrigatório - que passou a ser de 4 a 17 anos - para atender aos objetivos de universalização, garantia de padrão de qualidade e equidade (art. $212, \S 3^{\circ}$ ) (MARTINS, 2015, p. 168).

A meta à qual refere-se o financiamento da educação é a 20 e gerou diversas discussões, até a redação final do texto (MARTINS, 2015). Discussões em relação ao percentual do Produto Interno Bruto (PIB) e de royalty do 
pré-sal a serem investidos à educação, bem como a indicação de responsáveis e de prazos para a definição do CAQ, à fixação do CAQi e do prazo de implementação do CAQ, à exclusão de aposentadorias dos cálculos do MDE, e, por fim, ao aumento das porcentagens de investimentos dos entes federados no regime de colaboração financeira.

Relacionando alguns aspectos à promoção da educação infantil, o segundo PNE definiu: a universalização do ensino fundamental para 9 anos, a educação especial, a educação integral, a qualidade da educação básica, a formação e a valorização de professores, assim como a ampliação do financiamento. No que se refere à meta 1, não foram realizadas mudanças consideráveis, mantendo-se a redação do texto muito próxima à apresentada no PNE de 2001 (XIMENES; GRINKRAUT, 2014). Nesse viés, é possível destacar a mudança dos termos universalizar em vez de ampliar, ao se referir ao ensino de crianças de 4 e 5 anos. Desse modo, o novo PNE viria a cumprir com os objetivos da CF/88, que ampliou, em 2009, a obrigatoriedade do ensino para as crianças de 4 a 17 anos, bem como o atendimento de $50 \%$ das crianças de até 3 anos, meta já estabelecida anteriormente, mas com o prazo prolongado para a efetivação até 2024 .

Buscou-se explicitar o lugar da educação infantil junto a alguns marcos legais ${ }^{4}$ da educação brasileira, a fim de, na próxima seção, debater os avanços e os limites do Fundeb. Desse modo, verificar a importância, ou não, de sua permanência dentro da política de fundos para a qualidade da educação brasileira, com foco na educação infantil.

Avanços e limites do FUNDEB: um debate sobre as perspectivas com o fìm da vigência do fundo para a educação infantil

Sabe-se que o Fundeb foi criado com o intuito de realizar uma educação de qualidade. Ao longo do texto da Lei no 11.494 , o compromisso com uma educação de qualidade é retomado diversas vezes, mas é no artigo 38 que se observa a responsabilização atribuída à União, aos Estados e aos Municípios em relação à melhoria da qualidade de ensino e à definição de padrões mínimos de qualidade. Assim, o maior avanço do Fundo consiste em considerar toda a educação básica no processo de uma distribuição equânime das verbas destinadas à educação por meio da redistribuição de recursos, a fim de que munícipios mais abastados e menos abastados recebam um valor mínimo fixado por matrícula, em regime de colaboração, por intermédio de uma ação supletiva, acabando com a velha rixa entre Estados e Munícipios. Nesse sentido, o Fundeb foi o primeiro a incluir a educação infantil, garantindo recursos para essa etapa de ensino, visto que, anteriormente, Munícipios e Estados disputavam pelas matrículas do ensino fundamental, a fim de ampliar as verbas recebidas pelo Fundef.

Nessa perspectiva, cada rede de ensino procurava ampliar o seu atendimento, a fim de receber um repasse maior de recursos do Fundef. Para tanto, as redes de ensino recorriam a campanhas publicitárias, no início de cada ano, com vistas a atrair mais alunos. Várias foram as estratégias adotadas pelas redes estaduais e municipais para ampliar as matrículas, uma vez que, no contexto de um mesmo município, geralmente, havia escolas municipais e estaduais realizando o mesmo atendimento. Assim, dependendo do contexto de cada estado, as matrículas do ensino fundamental passaram a ser objeto de disputa entre estado e município.

Além dos recursos e diante do compromisso do Fundeb com a qualidade de ensino, está também a valorização dos profissionais do magistério. Por essa lógica, pensar a valorização docente, é pensar na remuneração do

${ }^{4}$ Para debate a respeito de outros documentos legais e normativos para a etapa, ver Bortot (2018). 
professor, nos planos de carreira, na capacitação, assim como nas condições de trabalho e de infraestrutura escolar. Nesse sentido, a Lei $\mathrm{n}^{\mathrm{o}}$ 11.738/2008 estipulou o piso salarial para a categoria docente de toda a educação básica, não permitindo que a remuneração seja inferior ao valor estipulado. Além disso, determinou que 33\% da carga de trabalho dos professores seja direcionada para atividades extraclasse.

Vale destacar que, na educação infantil, a lei representou um avanço ainda maior ao modificar a característica dos profissionais da educação infantil, uma vez que estão em regime de crescente profíssionalização, com exigências de formação e de qualificação. De acordo com Vieira (2011), mais de 40\% dos profissionais da educação infantil possuíam formação em nível superior, porém, a autora ressalta que ainda há muitos profissionais sem qualificação adequada para atendimento à criança pequena. Nessa lógica, 14\% dos professores da educação infantil contam apenas com formação no ensino fundamental ou médio.

Outra contribuição do Fundeb refere-se à promoção de mais condições para a universalização da educação básica e para a redução das taxas de analfabetismo. Nessa perspectiva, outro ponto fundamental atribuído ao Fundo são as formas de controle social por meio dos conselhos, destaque em relação ao Fundef, que teve a obrigatoriedade de constituir um conselho de forma genérica, formado por pessoas de confiança do governo.

Nesse viés, o Conselho de Acompanhamento e Controle Social (CACS), no Fundeb, conforme Bassi e Camargo (2009), adquiriu novas funções além verificar a distribuição, a transferência e a aplicação dos recursos do Fundo. Ademais, supervisionar o censo escolar e a proposta orçamentária, bem como acompanhar a aplicação dos recursos federais. Esses órgãos são formados por diversos membros representantes da sociedade civil, organizados com no mínimo 14 membros para conselho federal, 12 membros para o conselho estadual e 9 membros para o conselho municipal, além de mais 1 representante para o conselho municipal de educação e 1 representante para o conselho tutelar.

Reforça-se o fato de o maior avanço do Fundeb ter sido a inclusão de toda a educação básica na política de financiamento, contudo, concomitantemente, é possível destacar esse também como um limite. Ao substituir o Fundef, que subvinculava verbas apenas para o ensino fundamental, pelo Fundeb, que atende toda a educação básica, não houve expansão significativa dos recursos, pois ao vincular mais matrículas ao novo Fundo não se garantiu o aumento financeiro.

Nessa lógica, a redistribuição de verbas garantiu uma equidade parcial aos Estados, pois garantiu a vinculação de percentual para cada ente, mas não sobre o mesmo montante de arrecadação, além de, algumas vezes, redistribuir o recurso de munícipios que não têm condições para ampliar sua rede de atendimento e acabam, por vezes, não propiciando infraestrutura mínima ao atendimento educacional. No que se refere às regras de distribuição de fundos, o fator de ponderação é explicado por Militão (2010, p. 1) como desigual entre as etapas de ensino.

\footnotetext{
A mais preocupante refere-se à definição das ponderações aplicáveis à distribuição proporcional dos recursos do FUNDEB (base para fixação de valores aluno/ano diferenciados para etapas, modalidades e estabelecimentos da educação básica), que beneficiou Estados em prejuízo dos municípios. Para creche e pré-escola foram fixados fatores de ponderação (0,80 e 0,90 respectivamente) inferiores aos do ensino médio $(1,20$ a 1,30). Além de não condizentes com as elevadas despesas correntes das creches e pré-escolas, os fatores atribuídos a ambas inviabilizam a criação/ampliação de redes municipais de educação infantil e impedem, na prática, que tal etapa saia da condição de "primo pobre" da educação básica.
}

No que concerne principalmente ao atendimento da educação infantil, estudiosos apontam como uma crítica a contabilização das matrículas em redes particulares de ensino na distribuição de verbas do Fundeb, o 
que caracteriza uma terceirização das obrigações do munícipio. Vieira (2011) afirma que, em 2009, 52,1\% das instituições que atendiam educação infantil eram conveniadas.

Canavieira e Doihara (2009) apontam os desafios dessa expansão de atendimento por meio de convênios pelo menor valor do estudante em escolas conveniadas, bem como a dificuldade das secretarias municipais de educação para controlar e para fiscalizar esses locais de ensino, enfatizando a qualidade de atendimento e a capacitação e a valorização profissional.

Nessa lógica, o controle, a fiscalização e o direcionamento correto de recursos públicos são desafios a serem enfrentados nas políticas de financiamento brasileiras. No que diz respeito à educação infantil:

\begin{abstract}
A tentação, nesta nova fase, é a educação assumir, no que diz respeito à criança pequena, funções para além de sua missão, de sua competência, de seus recursos. Ou melhor, usar seus recursos para outras funções que não as da educação. Direcionar os recursos do FUNDEB para a salvação da criança brasileira estimula forte tentação. Porém, bem-estar integral da criança brasileira é uma tarefa que exige recursos múltiplos, integrados, contando com a educação, mas não somente com ela (ROSEMBERG, 2007, p. 10).
\end{abstract}

A lógica de redistribuição restringe o gasto com a educação a um percentual mínimo de divisão do valor arrecadado por meio de impostos. Nesse sentido, o valor arrecadado precisa ser dividido pelo número de matrículas que as escolas possuem, contudo, não se considera o valor necessário para a efetivação de uma educação de qualidade.

[...] a política de fundos não é um mecanismo novo, mas um novo momento da operação da vinculação da receita, entretanto, contém em si uma ruptura em relação à lógica de que é suficiente que cada rede de ensino opere exclusivamente com os recursos que o ente federado que a mantém pode arrecadar (GOUVEIA; SOUZA, 2015, p. 60).

Como demostrado, a redistribuição gera um ciclo vicioso. A falta de ampliação da rede faz com que não recebam mais verbas, portanto, sem verba sem matrícula/sem matrícula sem verba. Nessa lógica, Gaspar (2010) destaca que o problema seria sanado a partir da implantação conjunta do Fundeb e do CAQ.

\footnotetext{
Nessa perspectiva, avaliar o impacto do FUNDEB na qualidade da educação infantil é, dentre outros aspectos, considerar sua repercussão em relação ao valor mínimo a ser gasto por aluno que deverá incidir sobre o princípio estabelecido de igualdade no gasto por aluno da educação infantil; perceber sua efetivação como primeira etapa da educação básica no aumento da matrícula da educação infantil, e apreender o alcance da valorização do magistério expressa através da melhoria do salário do professor e da sua qualificação (GASPAR, 2010, p. 128).
}

Apesar da vinculação nos recursos ser um avanço, não significa que a educação brasileira atingiu a qualidade esperada, uma vez que os entes federados buscam subterfúgios para diminuir a colaboração. Segundo Gouveia (2011), o sistema tributário é composto por impostos, taxas e contribuições, no entanto, apenas os impostos entram na vinculação e essa determinação de contabilização de apenas impostos para a formação do Fundo apresenta problemas. "Como fundo contábil resultante de impostos, há dois problemas: 1) o fato de que, desde o Fundef, o Governo Federal vem criando taxas e não impostos, o que desonera a educação de arrecadar; e 2) o problema das isenções fiscais" (FERREIRA, 2014, p. 206).

Na busca pela qualidade, garantida pela CF/88, no artigo 206 da LDB, definiu-se a criação de padrões mínimos de qualidade, com variados insumos necessários para se efetivar educação resultando nos valores do 
CAQ e o CAQi. Esses mecanismos, previstos em Lei, são resultados de uma campanha realizada entre 2002 e 2005, orientada pela Campanha Nacional pelo Direito à Educação. Por meio de oficinas e seminários, com diversos seguimentos da sociedade civil, foram discutidas formas de se atingir os padrões mínimos de realização de uma educação de qualidade.

O CAQi consta nos documentos finais da Conferência Nacional de Educação Básica (Coneb), de 2008, e da Conferência Nacional de Educação (Conae), de 2010, e, após ampla discussão, foi aprovado por unanimidade pela Câmara de Educação Básica (CEB) do CNE, em maio de 2010, na forma do Parecer CNE/CEB nº 8/2010. Assim, o conceito do CAQi foi incluído em 4 dos 12 fins descritos na meta 20 definidas pelo PNE, Lei 13.005/2014, que em resumo apresentaram prazo de vigência para implantação, forma de cálculo, realização de acompanhamento regular dos indicadores e determinação da complementação da união aos entes que não atingirem o valor do CAQ.

Para regulamentar o processo de implantação, foi elaborado o parecer $n^{\circ}$ 8/2010 que expõe as legislações que defendem a necessidade de padrões mínimos de qualidade: a CF/88 traz a garantia de padrões de qualidade nos art. 206 e art. 211; a LDB, no artigo 3 e 4, também destaca a garantia de padrões de qualidade; e a Lei ${ }^{\circ}$ 9.131/95 delibera sobre as funções do CNE. Entre as funções desse Conselho estão analisar e buscar soluções para problemas da educação, analisar e emitir pareceres sobre as avaliações nas diferentes modalidades e analisar a aplicação da legislação sobre a educação. Além disso, traz o CAQi como referência para criação desses padrões de qualidade.

Ademais, o parecer relata ainda que construção de uma educação qualificada perpassa pela valorização docente, pelo financiamento e pela gestão da educação e pelo estabelecimento de padrões mínimos de qualidade a todas as escolas públicas. Para atingir esses objetivos e efetivar o CAQi, é necessário considerar os seguintes parâmetros de qualidade: 1) remuneração docente compatível com outras funções na qual se exija mesmo nível de formação, com uma jornada de $40 \mathrm{~h}$ em uma mesma instituição de ensino, adicional de $50 \%$ a profissionais que possuam nível superior em organizações em que possuem formados em nível médio com habilitação técnica, bem como a remuneração de $70 \%$ aos profissionais que possuem nível fundamental comparados aos profissionais de nível médio; 2) existência de profissionais de apoio técnico e administrativo que garantam o andamento da escola; 3) existência de creches e escolas com condições de infraestrutura e equipamentos adequados; 4) definição de relação professor/estudante adequada a um atendimento de qualidade.

O CAQi foi criado devido à dificuldade de criar um parâmetro de qualidade único, uma vez que cada etapa, modalidade e região possui sua especificidade para então realizar o cálculo do CAQ. Assim, o parâmetro estipulou padrões mínimos de qualidade que pudessem ser reconhecidos em todas as escolas. Cabe destacar que esses cálculos são feitos apenas para os insumos e para a manutenção, não para a construção de novas instituições de ensino. Esses investimentos seriam realizados de uma só vez pela administração no início da implantação - o que foi chamado de CAQi zero -, a fim de garantir a valorização profissional, a melhoria de infraestrutura e a garantia de relação (número) estudante/professor.

$\mathrm{O}$ custo da educação infantil, principalmente para as crianças na faixa de 0 a 3 anos, se justifica pelas especificidades necessárias para a faixa etária. Nessa lógica, a relação profissional/criança indica a necessidade de uma quantidade maior de profissionais. Além disso, a carga horária de atendimento idealmente determinada pelo CAQi deve ser de $6 \mathrm{~h}$ diárias, e os equipamentos e insumos devem ser adequados à faixa etária, assim como a alimentação. 
Com todas essas especificações, para se alcançar uma educação de qualidade, é evidente que o CAQi é muito maior que os recursos disponibilizados pelo Fundeb. Para evidenciar essa questão, a Tabela 1 apresenta a comparação do ano de 2008, com diferença, principalmente, na verba para educação infantil, enquanto etapa que necessita de maior custo/investimento para efetivação.

Tabela 1 - Comparação entre os valores estimados pelo caqi, para cada uma das etapas da educação básica, e os valores aplicados pelo FUNDEB/2008 por aluno/ano. valores em reais (R\$)

\begin{tabular}{l|c|c|c}
\hline $\begin{array}{l}\text { Etapa da Educação } \\
\text { Básica }\end{array}$ & $\begin{array}{l}\text { Valores previstos pelo CAQi - } \\
\text { ano 2008 }\end{array}$ & FUNDEB - 2008 & (CAQi - FUNDEB) \\
\hline Creche & $5.943,60$ & $1.251,00$ & $+4.692,60$ \\
\hline Pré-Escola & $2.301,24$ & $1.024,00$ & $+1.277,24$ \\
\hline $\begin{array}{l}\text { Etapa da Educação } \\
\text { Básica }\end{array}$ & $\begin{array}{l}\text { Valores previstos pelo CAQi - } \\
\text { ano 2008 }\end{array}$ & FUNDEB - 2008 & (CAQi - FUNDEB) \\
\hline $\begin{array}{l}\text { Ensino Fundamental - } \\
\text { anos iniciais }\end{array}$ & $2.194,56$ & $1.137,00$ & $+1.057,56$ \\
\hline $\begin{array}{l}\text { Ensino Fundamental - } \\
\text { anos finais }\end{array}$ & $2.148,84$ & $1.251,00$ & $+933,84$ \\
\hline Ensino Médio & $2.209,80$ & $1.365,00$ & $+844,80$ \\
\hline $\begin{array}{l}\text { Ensino Fundamental } \\
\text { - Educação do Campo - } \\
\text { anos iniciais }\end{array}$ & $3.627,12$ & $1.194,00$ & $+2.433,12$ \\
\hline $\begin{array}{l}\text { Ensino Fundamental } \\
\text {-Educação do Campo - } \\
\text { anos finais }\end{array}$ & $2.773,68$ & $1.308,00$ & $+1.465,68$ \\
\hline
\end{tabular}

Fonte: Brasil (2010, p. 37).

Infelizmente, o valor destinado à educação pela disponibilidade orçamentária está muito aquém de garantir o mínimo de qualidade estabelecido, com a justificativa que "[...] a maioria dos governos alega aplicar apenas o percentual mínimo, como se isso fosse suficiente para atender as necessidades educacionais da população" (DAVIES, 2006, p. 755).

Conforme Ximenes (2014), o poder público alega a insuficiência de recursos para efetivar mais investimentos na educação. Além disso, “[...] o Poder Público utiliza-se frequentemente da alegação de falta de recursos para justificar sua impossibilidade de realizar certos direitos consagrados no ordenamento jurídico, inclusive nos tribunais pátrios, por meio da 'reserva do possível"” (TAPOROSKI, 2016, p. 8). Esse princípio possibilita ao Estado se limitar às existências orçamentárias no cumprimento dos direitos sociais/existenciais. Por essa lógica, alegar a reserva do possível, a efetivação dos direitos limitada à disponibilidade orçamentária, atinge a própria Constituição, no artigo 211, ao determinar que a função da União é supletiva e redistributiva na efetivação de uma educação de qualidade, ou seja, de complementação quando os entes não atingem o valor mínimo necessário à sua efetivação.

É inegável a necessidade de maior investimento na educação, porém, além de estar longe da realidade necessária, ela é fundamental para assegurar as condições equânimes de qualidade. Por esse viés, conforme Martins, “O fim do Fundeb provocaria grande desorganização no financiamento da educação básica pública brasileira e 
colocaria termo à mais importante experiência de construção de encaminhamento de políticas públicas a partir da solidariedade federativa" (2014, p. 131).

Nesse sentido, o da continuidade da política pública de estado justifica-se. Por exemplo, no ano de 2018, de acordo com informações do Fundo Nacional de Desenvolvimento da Educação (FNDE), nove estados do norte e do nordeste (Alagoas, Amazonas, Bahia, Ceará, Maranhão, Pará, Paraíba, Pernambuco e Piauí), receberam complementação do Fundeb, pois não atingiram o valor mínimo por aluno.

Para a previsão de gastos do ano de 2018, a Portaria Interministerial no 10 , de 28 de dezembro de 2017, observou valores por estudante/ano dos diferentes níveis de modalidade da educação de todos os estados, na educação infantil, modalidade creche, o valor mínimo foi fixado em $\mathrm{R} \$ 3.921,67$, enquanto os estados com maior valor-aluno são Roraima, com R $\$ 6.079,74$, seguido pelo Rio Grande do Sul com R $\$ 5.389,36$; uma diferença de $55 \%$ entre o menor e o maior valor. Dessa forma, a descontinuidade da política acentuará as desigualdades regionais já existentes no país, gerando uma descompensação financeira ainda maior, a qual inviabilizaria a efetivação de qualquer política de educação de qualidade.

Sendo assim, a fim de tornar o Fundeb um fundo permanente, há uma Proposta de Emenda Constitucional (PEC), a n ${ }^{\circ} 15$ de 2015, apresentada na Câmara dos Deputados, com o objetivo de transferir o Fundo de Ato das Disposições Constitucionais Transitórias (ADCT) para o corpo permanente da Constituição, tornando-o instrumento de financiamento permanente da educação.

Para Martins (2015), transformar o Fundeb em um fundo permanente é fundamental, tendo em vista que o seu fim determina também o fim de seu valor jurídico, logo, sem nenhuma outra determinação, o financiamento da educação voltaria a ser igual ao período anterior, antes da política de fundos de redistribuição. Isso representaria um retrocesso para a educação, e, consequentemente, uma carência maior ao financiamento da educação infantil, que ainda não conseguiu atingir nem mesmo as metas de atendimento de $50 \%$ das crianças entre 0 e 3 anos estabelecidas no PNE (2014), tornando a educação precária e, em algumas situações, inviável. O novo Fundeb manteria as mesmas características já determinadas, redistribuindo recursos com base no número de matrículas e na origem financeira dos impostos, mantendo toda a educação básica e distribuindo os valores de forma ponderal.

Assim, Pinto (2015, p. 106) esclarece:

Cabe comentar que esse desequilíbrio entre os valores com os quais os municípios contribuem para o fundo e aqueles que eles recebem do respectivo governo estadual aponta para uma crise grave em um futuro próximo, dada a transitoriedade do Fundeb. É fundamental encontrar um mecanismo de financiamento permanente que regule essas relações antes de 2020, quando o fundo expira, sob pena de se instaurar o caos na educação básica.

Nesse sentido, as universidades federais do Paraná e de Goiás realizaram uma pesquisa para criar uma ferramenta que trouxesse um avanço importante para o financiamento da educação no Brasil, em relação a condições de qualidade. Essa ferramenta é o Simulador de Custo-Aluno-Qualidade (SimCAQ). A equipe que realizou a pesquisa é composta por professores, estudantes de graduação, de mestrado e de doutorado das áreas de Educação, Computação, Administração Pública, Design e Comunicação, além de analistas de sistemas contratados. O objetivo é oferecer suporte ao processo de elaboração e adequação, bem como monitoramento e avaliação dos Planos Estaduais e Municipais de Educação, visando articular as metas educacionais locais e as metas do 
PNE 2014-2024 à previsão do montante de recursos financeiros necessários para a oferta da educação básica em condições de qualidade no período dos planos. Além disso, o SimCAQ busca fomentar pesquisas e publicações sobre financiamento da educação, custos educacionais e oferta da educação básica em condições de qualidade; promover a interação entre pesquisadores, gestores das redes de ensino, governos, profissionais da educação e sociedade civil a fim de debater os desafios para o cumprimento da meta 20 do PNE 2014-2024 (SIMCAQ, 2019). A Tabela 2 apresenta os valores de referência entre o CAQ e o Fundeb, para creches e pré-escolas.

Tabela 2 - Valores de referência do CAQ e FUNDEB (2019) ${ }^{5}$

\begin{tabular}{c|c|c|c|c|c}
\hline \multirow{2}{*}{ Etapa } & \multirow{2}{*}{$\begin{array}{c}\text { Área da } \\
\text { Localidade }\end{array}$} & \multirow{2}{*}{ Turno } & \multirow{2}{*}{ CAQ 2019 } & \multicolumn{2}{|c}{ Valor-Aluno Fundeb } \\
\cline { 4 - 6 } & & $(\mathrm{R} \$)$ & $\left(\right.$ Menor $\left.^{1}\right)(\mathrm{R} \$)$ & $\left(\right.$ Maior $\left.^{2}\right)(\mathrm{R} \$)$ \\
\hline Creche & Urbana & Parcial & 10622 & 3724 & 4917 \\
\hline Creche & Urbana & Integral & 19132 & 4210 & 5558 \\
\hline Creche & Rural & Parcial & 17174 & 3724 & 4917 \\
\hline Creche & Rural & Integral & 25450 & 4210 & 5558 \\
\hline Pré-Escola & Urbana & Parcial & 6324 & 3400 & 4489 \\
\hline Pré-Escola & Urbana & Integral & 11147 & 4210 & 5558 \\
\hline Pré-Escola & Rural & Parcial & 8570 & 3400 & 4489 \\
\hline Pré-Escola & Rural & Integral & 17352 & 4210 & 5558 \\
\hline
\end{tabular}

Fonte: organizado pelas autoras a partir do SimCAQ, 2019.

Os dados revelam o quão distante o Fundeb está de assegurar um patamar mínimo de qualidade como o definido pelo CAQ, pois nota-se a enorme discrepância, particularmente, nos valores referentes às creches. Assim, o CAQi foi o primeiro passo para um ensino de qualidade, contudo, o horizonte a ser atingido nessa caminhada é o CAQ.

Com a permanência do Fundeb, busca-se aliá-lo ao CAQ para efetivar os critérios para uma educação de qualidade. Nesse sentido, o CAQ define critérios de qualidade para melhor distribuir os recursos, atuando como “[...] instrumento para atingir os fins mencionados, posicionou-se no centro da interpretação desse dispositivo constitucional. Enquanto o Fundeb e o salário-educação são fontes, o CAQ é um critério de alocação de recursos" (SENA, 2015, p. 12).

A partir da pesquisa, observou-se que a continuidade do Fundeb é fundamental, pois com sua ausência espera-se um acirramento das desigualdades, da qualidade, da valorização profissional, bem como maior descentralização, o que pode gerar um crescimento nas propostas de convênios, sobretudo, na educação infantil. Ao não efetivar o Fundeb como mecanismo de combate às desigualdades, com valores mínimos fixados em cada estado, as diferenças existentes no país devem crescer, além de distanciar a possibilidade de alcançar o valor do CAQi, bem como de garantir uma educação de qualidade no Brasil.

No que se refere à educação infantil, delegada a responsabilidade ao munícipio, ente federado com menor capitação de recursos, a descontinuidade e as rupturas dificultarão não só a efetivação da qualidade como um todo, mas, principalmente, o acesso, conforme estabelecido no PNE, visto que a ampliação das vagas não é apenas dever do Estado, mas um direito da criança e parte do seu reconhecimento como sujeito de direitos.

$\overline{{ }^{5} \text { Valores da PI n }{ }^{\circ} 10 \text {, de }} 28$ de dezembro de 2017, e anexos disponíveis no site do FNDE. 


\section{Considerações finais}

À guisa de conclusão, considera-se que, por meio da política de redistribuição de valores e taxas ponderais, a política de fundos reconhece que cada modalidade possui suas especificidades, logo, as verbas devem considerar os gastos para o público a ser atendido. Desse modo, a consideração das diversas formas de se efetivar a educação infantil, bem como as elevações de taxa demostram um reconhecimento das especificidades desta etapa de ensino, que é a mais onerosa da educação brasileira devido à necessidade de um número reduzido de crianças por turma, consequentemente, um número maior de profissionais para atender a demanda, estrutura física e material adequada que apresenta um custo maior.

Assim, para caminhar e avançar nas questões pertinentes ao financiamento da educação brasileira, o principal passo, hoje, é manter o Fundeb como fundo de financiamento para então, realizando as modificações necessárias para o aumento de financiamento, garantir que o CAQ seja uma realidade, tanto para a equidade quanto para a qualidade. Além disso, esse mecanismo será uma de suas principais fontes - não a única, porque o CAQ deve considerar todos os recursos destinados à educação. Nesse sentido, a aprovação do novo Fundeb é o principal passo para que se alcance o CAQ.

Contudo, essa discussão sofreu uma reviravolta com a sanção da Portaria nº 649, de 22 de março de 2019, que altera dispositivos da Portaria $\mathrm{n}^{\circ}$ 233, de 15 de março de 2018, pois, de acordo com o prof. Dr. Salomão Ximenes, redefine o Comitê Permanente de Avaliação de Custos na Educação Básica do Ministério da Educação (CPACEB), criado em 2016, excluindo de sua composição o Fórum Nacional de Educação (FNE), última brecha de participação da sociedade civil, e incluindo os Ministérios do Planejamento e da Economia. Além disso, extingue a menção à implementação do CAQi e do CAQ, bem como do levantamento de fontes de financiamento para viabilizar sua implementação.

Apesar do CNE ter normatizado o CAQi e o CAQ e esses terem sido incluídos no PNE, o MEC nunca homologou essa normatização. Ao retomar o artigo 214 da $\mathrm{CF} / 88$, que estabelece a efetivação de um plano nacional, no qual está firmado o projeto de financiamento por meio do CAQi e do CAQ, além da definição de uma participação mais efetiva da União para efetivação, esses não se concretizaram. Atualmente, com o argumento da falta de dados e da não responsabilidade do CNE, em conjunto com o MEC, sobre esses mecanismos, o Governo Federal resolveu excluir o planejamento do custo/aluno da pasta, transferindo ao Ministério da Economia a função de definir parâmetros de qualidade da educação, decisão que, na opinião de Ximenes (2019), deixaria o financiamento subordinado aos limites econômicos.

Os antigos desafios, somados aos limites atuais, engendraram inquietações que percorreram este estudo durante o final de 2018 até março de 2019. Além de chamar a atenção pela atuação fundamental do Fundeb para a qualidade da educação infantil, hoje, estende-se estas considerações finais também aos outros mecanismos de financiamento ameaçados na conjuntura atual, anteriormente mencionados. Em 2019, caberá ao Congresso Nacional manter o ritmo e o alto nível das discussões, mas caberá a toda a sociedade engajamento nessa virada do rumo em relação às oportunidades educacionais, as quais devem ser iguais para todos. Será imprescindível simular impactos das propostas e debatê-las democraticamente, uma vez que é necessário um debate amplo, corajoso e qualificado sobre as potencialidades futuras do sistema de financiamento da educação básica, as quais refletirão nas oportunidades de aprendizagem das próximas gerações. 


\section{Referências}

ARAÚJO, L. Impacto financeiro da implantação do CAQi no Brasil. Educ. Soc., Campinas, v. 40, e0181802, 2019. Disponível em: http://www.scielo.br/pdf/es/v40/1678-4626-es-40-e0181802.pdf. Acesso em: ${ }^{10}$ mar. $r \cdot 19$.

BASSI, M. E.; CAMARGO, R. B. de. Participação e controle social no Fundef e no Fundeb. Revista Poiésis, Tubarão, v. 2, n. 1, p. 105-118, jan./jun. 2009. Disponível em: https://www.researchgate.net/ publication/49620324_Participacao_e_controle_social_no_Fundef_e_no_Fundeb. Acesso em: ${ }^{\circ} \mathrm{mar}$. r.19.

BARROS, M. D. Educação infantil: o que diz a legislação. Disponível em: https://lfg.jusbrasil.com. br/noticias/168958/artigos-educacao-infantil-o-que-diz-a-legislacao. Acesso em: 10 mar. 2019.

BORTOT, C. M. Atores e autores de políticas para a Educação Infantil de zero a três anos no Brasil: transformação do estado e das suas relações com a sociedade civil (2000-2015). 255f. Dissertação (Mestrado em Educação) - Universidade Estadual de Maringá. Maringá, 2018.

BRASIL. Conselho Nacional de Educação. Parecer CNE/CEB n $\mathbf{n}^{0}$ 8/2010, aprovado em 5 de maio de 2010. Brasília, 2010a. Disponível em: http://migre.me/weWVT. Acesso em: 10 mar. 2019.

BRASIL. Constituição (1988). Emenda Constitucional n 53, de 19 de dezembro de 2006. Dá nova redação aos art. $7^{\circ}, 23,30,206,208,211$ e 212 da Constituição Federal e ao art. 60 do Ato das Disposições Constitucionais Transitórias. Diário Oficial da União, Brasília, 20 dez. 2006. Disponível em: http://www.planalto.gov.br/ccivil_03/constituicao/Emendas/Emc/emc53.htm. Acesso em: 1 mar. 2019.

BRASIL. Lei no 11.494, de 20 de junho de 2007. Regulamenta o Fundo de Manutenção e Desenvolvimento da Educação Básica e de Valorização dos Profissionais da Educação - Fundeb. Brasília, 2007. Disponível em: http://migre.me/weX1Q. Acesso em: 10 mar. 2019.

BRASIL. Lei $\mathbf{n}^{\mathbf{0}} \mathbf{1 3 . 0 0 5}$, de 25 de junho de 2014. Aprova o Plano Nacional de Educação e dá outras providências. Brasília, 2014. Disponível em: http://migre.me/weWXb. Acesso em: 10 mar. 2017.

BRASIL. Ministério da Educação. Documento Final da Conferência Nacional de Educação CONAE 2010. Brasília: MEC, 2010. Disponível em: http://conae.mec.gov.br/images/stories/pdf/pdf/ documetos/documento_final_sl.pdf. Acesso em: 1 mar. 2019.

CANAVIEIRA, F. O; DOIHARA, L. F. A Política de Conveniamento para atendimento de Educação Infantil em São Luís: solução ou impasse? In: JORNADA NACIONAL DE POLÍTICAS PÚBLICAS, 4., 2009. Anais [...]. São Luís, 2009. Disponível em: http://www.joinpp.ufma.br/jornadas/joinppIV/ eixos/11_educacao/politica-de-conveniamento-para-atendimento-da-educacao-infantil-em-sao-luisimpasse-ou-solucao.pdf. Acesso em: 1 mar. 2019.

DAVIES, N. FUNDEB: a redenção da educação básica? Educação \& Sociedade, v. 27, n. 96, out., 2006, pp. 753-774. Centro de Estudos Educação e Sociedade. Campinas, Brasil. Disponível em http:// www.scielo.br/pdf/es/v27n96/a07v2796.pdf. Acesso em $1^{\circ}$ mar. 2019. 
FERREIRA, G. S. Uma conquista histórica, o Fundeb está em risco. Cadernos de Educação, Brasília, n. 27, p. 191-211, jul./dez. 2014. Disponível em: https://www.cnte.org.br/images/stories/cadernos_ educacao/cadernos_educacao_27.pdf. Acesso em: 1 mar. 2019.

GASPAR, M. L. R. Os impactos do FUNDEB na Educação Infantil brasileira: oferta, qualidade e financiamento. Evidência, Araxá, n. 6, p. 121-136, 2010. Disponível em: https://www.uniaraxa.edu.br/ ojs/index.php/evidencia/article/view/213. Acesso em: 1 mar. 2019.

GOUVEIA, A. B. O financiamento da educação no Brasil e o desafio da superação das desigualdades. In: SOUZA, Â. R.; GOUVEIA, A. B.; TAVARES, T. M. (Org.). Políticas educacionais: conceitos e debates. Curitiba: Editora Appris, 2011.p.83 - 105.

GOUVEIA, A. B; SOUZA, Â. R. A política de fundos em perspectiva histórica: mudanças de concepção da política na transição Fundef e Fundeb. Em Aberto, Brasília, v. 28, n. 93, p. 45-65, jan./ jun. 2015. Disponível em: http://emaberto.inep.gov.br/index.php/emaberto/article/view/2457. Acesso em: 1 mar. 2019.

MARTINS, P. S. Passado, presente e futuro do mecanismo central de financiamento da educação básica brasileira. Cadernos de Educação / Confederação Nacional dos Trabalhadores em Educação (CNTE). - Ano XVIII, n.27, jul./dez. 2014. Brasília: Confederação Nacional dos Trabalhadores em Educação. Disponível em: https://www.cnte.org.br/images/stories/cadernos_ educacao/cadernos_educacao_27.pdf. Acesso em $1^{\circ}$ mar. 2019.

MARTINS, P. S. A PEC No 15/2015 e o novo FUNDEB. Nota técnica. Outubro, 2015. Disponível em: https://www2.camara.leg.br/atividade-legislativa/estudos-e-notas-tecnicas/publicacoes-da-consultorialegislativa/areas-da-conle/tema11/a-pec-no-15-2015-e-o-novo-fundeb-paulo-de-sena. Acesso em: 1 mar. 2019.

MILITÃO, S. C. N. Do Fundef ao Fundeb: o que muda para o financiamento da educação municipal? Colloquium Humanarum, v. 7, n. 2, 2010.

MOREIRA, J. A. da S.; LARA, A. M. de B. Políticas públicas para a Educação Infantil no Brasil (1990-2001). Maringá: Eduem, 2012. Disponível em: http://books.scielo.org/id/kcv6j/pdf/ moreira-9788576285854.pdf. Acesso em: 1 mar. 2019.

OLIVEIRA, R. P. de; ARAUJO, G. C. de. Qualidade do ensino: uma nova dimensão da luta pelo direito à educação. Rev. Bras. Educ., Rio de Janeiro, n. 28, p. 5-23, abr. 2005. Disponível em: http:// www.scielo.br/scielo.php?pid=s1413-24782005000100002\&script=sci_abstract\&tlng=pt. Acesso em: 23 nov. 2019.

PASCHOAL, J. D.; MACHADO, M. C. G. A história da Educação Infantil no Brasil: avanços, retrocessos e desafios dessa modalidade educacional. Revista Histedbr on-line. Campinas, $\mathrm{n}^{\mathbf{0}} 33$, $\mathrm{p}$. 78-95, março de 2009. Disponível em: http://www.histedbr.fe.unicamp.br/revista/edicoes/33/art05_33. pdf. Acesso em: 1 mar. 2019.

PINTO, J. M. de R. O financiamento da educação na Constituição Federal de 1988: 30 anos de mobilização social. Educ. Soc., Campinas, v. 39, n. 145, p. 846-869, Dec. 2018. Disponível em: http://www.scielo.br/scielo.php?script=sci_arttext\&pid=S0101-73302018000400846\&lng=en\&nrm=i so. Acesso em: 23 nov. 2019. 
PINTO, J. M. R. As implicações financeiras da municipalização do Ensino Fundamental.

Dissertação (Mestrado). Faculdade de Educação da UNICAMP, Campinas, 1989. Disponível em: http://repositorio.unicamp.br/jspui/handle/REPOSIP/252258. Acesso em: 1 mar.2019.

PINTO, J. M .R. O Fundeb na perspectiva do custo aluno qualidade. Em Aberto, Brasília, v. 28, n. 93, p. 101-117, jan./jun. 2015. Disponível em: http://emaberto.inep.gov.br/index.php/emaberto/article/ view/2460. Acesso em: 1 mar. 2019.

ROSEMBERG, F. Educação infantil pós-FUNDEB: avanços e tensões. In: SEMINÁRIO EDUCAR NA INFÂNCIA: PERSPECTIVAS HISTÓRICO-SOCIAIS. 2007. Anais [...]. Curitiba, agosto, 2007. Disponível em: http://www.diversidadeducainfantil.org.br/PDF/Educa\%C3\%A7\%C3\%A3o\%20 infantil $\% 20 \mathrm{p} \% \mathrm{C} 3 \% \mathrm{~B} 3 \mathrm{~s}-\mathrm{FUNDEB} \% 20 \mathrm{avan} \% \mathrm{C} 3 \% \mathrm{~A} 7 \mathrm{os} \% 20 \mathrm{e} \% 20$ tens $\% \mathrm{C} 3 \% \mathrm{~B} 5 \mathrm{es} \% 20-\% 20$ F\%C3\%BAlvia\%20Rosemberg.pdf. Acesso em: 1 mar.2019.

TAPOROSKI, B. C. H. O valor anual mínimo por aluno do FUNDEB, o CAQi e a reserva do possível. Fineduca - Revista de Financiamento da Educação, Porto Alegre, v. 6, n. 6, 2016. Disponível em: https://seer.ufrgs.br/fineduca/article/view/62847. Acesso em: 1 mar. 2019.

TOMASEVSKI, K. Human Rigths Obligations in Education: the 4-A scheme. Nijmegen: Wolf Legal Publishers, 2006.

VIEIRA, L. M. F. Obrigatoriedade escolar na educação infantil. Revista Retratos da Escola, Brasília, v. 5, n. 9, p. 245-262, jul./dez. 2011. Disponível em: http://retratosdaescola.emnuvens.com.br/rde/ article/viewFile/9\%20/173. Acesso em: 1 mar. 2019.

XIMENES, S. B. O Conteúdo Jurídico do Princípio Constitucional da Garantia de Padrão de Qualidade do Ensino: uma contribuição desde a teoria dos direitos fundamentais. Educ. Soc., Campinas, v. 35, n. 129, p. 1027-1051, Dec. 2014. Disponível em: http://www.scielo.br/scielo. php?script $=$ sci_arttext\&pid=S0101-73302014000401027\&lng=en\&nrm=iso. Acesso em: 23 nov. 2019.

XIMENES, S. GRINKRAUT, A. PNE: parâmetros de planejamento, efetivação e exigibilidade do direito. Caderno Cenpec, São Paulo, v.4, n.1, p.78-101. jun. 2014. Disponível em: http://cadernos. cenpec.org.br/cadernos/index.php/cadernos/article/view/272/276. Acesso em: $1^{\circ}$ mar. 2019. 